\title{
Physical Exercise Improves Total Antioxidant Capacity and Gene Expression in Rat Hippocampal Tissue
}

\author{
F. FRANZONI'A, G. FEDERIGHI'2,A, J. FUSI', V. AGOSTA², E. CERRI' ${ }^{1}$, \\ R. BANDUCCI ${ }^{1}$, A. PETROCCHI ${ }^{1}$, R. BERNARDI ${ }^{3}$, A. INNOCENTI ${ }^{4}, \mathrm{C}$. PRUNETI ${ }^{4}$, \\ S. DANIELE ${ }^{5}$, S. PELLEGRINI ${ }^{1}$, C. MARTINI ${ }^{5}$, R. SCURI ${ }^{2}$, F. GALETTA ${ }^{1}$ \\ ${ }^{7}$ Department of Clinical and Experimental Medicine, University of Pisa, Pisa; \\ ${ }^{2}$ Department of Translational Research and New Technologies in Medicine and Surgery, University of Pisa, Pisa; \\ ${ }^{3}$ Department of Agrarian, Food and Agro-Environmental Sciences, University of Pisa, Pisa; \\ ${ }^{5}$ Department of Pharmacy, University of Pisa, Pisa; \\ ${ }^{4}$ Department of Clinical and Experimental Medicine, University of Parma, Parma, Italy; \\ A These authors equally contributed to the present work.
}

\begin{abstract}
A B S T R A C T
Exercise may exert beneficial effects on cognitive functions and play an important role in the prevention of neurodegenerative diseases. Such effects seem to be mediated by changes in anti-oxidative status, but limited information is available on the nature of molecular pathways supporting the antioxidant effects of exercise in the brain. In this study 3-5-month-old male Wistar albino rats were subjected to three times/week moderate intensity exercise on a rodent treadmill for a period of 6 weeks. The tissue antioxidant activity towards various reactive oxygen species (ROS) was determined in the hippocampus. In addition, to identify the molecular pathways that may be involved in ROS metabolism, the expression of nerve growth factor (NGF) and sirtuins (SIRT1 and SIRT3) were measured. Our results showed a higher antioxidant activity in the hippocampus of physically trained rats compared to sedentary controls. Furthermore, exercise induced an up-regulation of NGF, possibly related to an improved redox balance in the hippocampus. These results suggest that physical exercise might prevent ageinduced oxidative damage in the hippocampus.
\end{abstract}

\section{Key words \\ Physical activity $\bullet N G F \bullet$ Free radicals $\bullet$ SIRT1 $\bullet$ SIRT3}

\section{Introduction}

A number of studies have demonstrated that increased levels of reactive oxygen species (ROS) are involved in the aging process (Droge 2013) and contribute to pathological changes in neurodegenerative disorders (Floyd 2002). The hippocampus is particularly vulnerable to oxidative damage during aging due to the reduced capacity of neurons to maintain redox homeostasis (Serrano 2004). Since the hippocampus is involved in certain forms of learning and memory consolidation (Morris 2006), oxidative damage of this brain area may cause impairment in cognitive functions (Serrano 2004). The maintenance of a normal redox state in hippocampal neurons, therefore, is important for the prevention of cognitive decline during aging.

Numerous studies indicate that exercise may play an important role against age-associated cognitive decline (Mattson 2000; Kramer 1999; Kayser 2003; Bergensen 2006; Ferrari 2007; Shin 2009; Train the brain study 2017). The principal modification 
induced by regular exercise includes structural changes in the hippocampus, such as neurogenesis (Trejo 2001; Van Praag 1999; Okamoto 2012) and angiogenesis (Van der Borght 2009), which possibly contribute to functional improvement (Clark 2008). Unfortunately, the molecular mechanism underlying these exercise-induced structural changes is still unclear. It has been proposed that regular physical training induces an adaptation process in ROS-detoxifying systems, resulting in increased resistance of cells to oxidative challenges (Radak 1999a; Franzoni 2005). Previous studies on rat brain showed that exercise training reduces thiobarbituric acid reactive substances (TBARS) content and the DNA oxidative-damage marker 8-hydroxy-2'deoxyguanosine, as well as increases superoxide dismutase (SOD) antioxidant activity and the total antioxidant capacity (TAC) (Nonato 2016; Mahjoub 2016), thus protecting hippocampal cells against oxidative damage like some anticonvulsants and mood stabilizing drugs (Cui 2007; Mariotti 2010). Moreover, physical activity is able to influence neurotrophic factors (Mahjoub 2016) such as the brain-derived neurotrophic factor (BDNF) and the nerve growth factor (NGF), which modulate neuronal plasticity and survival by their protective effect against free-radical species and the increase in the activities of the antioxidant defences (Neeper 1996; Spina 1992; Nisticò 1992).

The exercise-induced antioxidant status may be regulated by the expression of Sirtuins, proteins with multiple enzymatic activities, including NAD+dependent deacetylation (Koltai 2010). The NAD+ requirement for their enzymatic activity makes them sensors of the redox state of the cell and organism. Thus, sirtuins are major effectors in the cellular response to oxidative stress, acting to modulate cellular physiology under these conditions. Mammals have 7 sirtuins, denoted SIRT1 to 7 (Pallas 2008). Among these, the increase of SIRT1 activity in human cells can delay apoptosis and protects from oxidative stress (Howitz 2003), while SIRT3 responds to changes in mitochondrial redox status by altering the enzymatic activity of manganese superoxide dismutase (MnSOD) (Ozden 2011). It was recently reported that SIRT3 overexpression protects cultured motor neurons against the cell death-promoting effect of a SOD1 mutation that causes familial amyotrophic lateral sclerosis (ALS) (Song 2013) and protects mice against noise-induced hearing loss (Someya 2010), suggesting neuroprotective roles for SIRT3. However, the mechanisms that regulate the expression of SIRTs in neurons, and their potential roles in neuronal responses to stress are unknown. Thus, in the present study the impact of an exercise training protocol on oxidative stress biomarkers and SIRT and NGF expression in rat hippocampus was investigated.

\section{Experimental Procedures}

\section{Animal care and training protocol}

The experiments were conducted with eight 3-5-monthold male Wistar albino rats (Charles River, Calco, Italy), weighing $280-300 \mathrm{~g}$ at the beginning of the study. Manipulation and animal care were performed in accordance with the guidelines of the Committee on Research Ethics of the IASP and Materials and with the Italian national law on the use of animals for research (DL116 / 92, application of Directive of the Council of European Communities 86/609 / EEC), and have been approved by the ethics committee of the University of Pisa (n. 00 Protocol 4896/2013).

The animals were used individually and maintained in conditions relaying standard constant temperature $\left(24 \pm 1^{\circ} \mathrm{C}\right)$ and humidity $(60 \pm 5 \%)$, food and water ad libitum and subjected to a circadian cycle of artificial light/dark of 12 hours.

We randomly assigned the rats to the following two experimental groups: untrained controls and one experimental group of exercise that underwent a 6-week moderate-intensity exercise training protocol for three times/week (Figure 1). In each exercise session, each animal was brought from the housing room to the training room, left for 15 minutes, and then removed manually from the home cage and placed into a specially constructed training apparatus. The conditioning apparatus consisted of a plastic wheel, $42 \mathrm{~cm}$ in diameter, closed at the rear and perforated along the whole outer surface, so that air and light penetrated inside. A transparent plastic panel wheel delimited a corridor along which the animal was forced to walk, following the rotary movement of the wheel. On the panel there was an externally hinged access door (with magnetic closure) to allow the input and the output of the animal. A metallic pedestal, $36 \mathrm{~cm}$ high, held an iron rod, $40 \mathrm{~cm}$ long, centrally inserted in the wheel, to 
support the entire structure and to allow the rotary movement around it, in both clockwise and schedule directions. A toothed belt connected to a step-bystep electric motor (US Digital, Washington 98684, USA) induced the rotational movement, operated by a computerized system. The computerized system, through a particular software programmed into the LAB VIEW system (National Instruments SRL, Milan, Italy), allowed the operator to manage the rotary movement of the wheel by setting the direction of rotation (clockwise or counter clockwise), the speed of rotation (expressed in $\mathrm{m} / \mathrm{min}$ ), the rotation time ( $\mathrm{min}$ ) the distance travelled $(\mathrm{m})$ and the data acquired in real time. Data recorded were stored on the table to be subsequently analysed offline.

The animals were habituated to the exercise room for 1 week before the exercise: the first two days they were left free to explore and move around inside the wheel, which was not connected to the software. In the following days, the wheel was driven slowly $(4-5 \mathrm{~m} / \mathrm{min}$ ) to allow the rat to coordinate their pace with the apparatus rotation speed. After 3-4 days of adaptation, the animals showed the ability to follow the movement of the wheel, walking continuously for 30 minutes. They were exercised for 6 weeks (Krause 2015), according to the following protocol: a) 3 sessions per week, on alternate days; b) all training sessions always take place between 10 am and 3 $\mathrm{pm}$, to reduce circadian influences; c) the rat, at the beginning of the session, was left undisturbed and autonomous in its movement for the first 5 minutes, after which the operator started the motor-induced movement of the wheel; d) each training session had a duration of 30 minutes, during which the rotation speed was increased to $1 \mathrm{~m} / \mathrm{min}$, every 15 minutes. As schematically depicted in Figure 1, the speed reached at the end of each session was the speed with which the next session started. In this way, starting from an initial speed of $5 \mathrm{~m} / \mathrm{min}$ (session 1), session after session, at the end of the fifth week, a speed of $20 \mathrm{~m} /$ min was reached. The speed reached in session 15 was also maintained during the last three sessions in the sixth week of training.

At the end of each training session, the animals were placed in their home cage and brought back into the enclosure. The sedentary rats, however, were taken to the training room with the trained rats, each session, but were left in their home cage for the entire duration of the workout.
One week after the last training session, all animals were sacrificed by cervical dislocation. Under sterile conditions and under a microbiological laminar flow hood, the brain was immediately removed from the skull, and kept on ice made from frozen saline; then the brain tissue was dissected in order to obtain sections of the hippocampus. Each tissue section was splitted into two samples: one was stored in 1.5 $\mathrm{ml}$ eppendorf at $-80^{\circ} \mathrm{C}$ to be subsequently used for the transcriptional analysis; the other sample was placed on ice and immediately homogenated to be used for the total oxyradical scavenging capacity (TOSC) assay. From different tissue samples, total RNA was extracted using the GenElute ${ }^{\mathrm{TM}}$ extraction kit Mammalian Total RNA Miniprep Kit, RTN70 (Sigma-Aldrich, St. Louis, MO, USA), as set forth by the company. The purified RNA samples were read by the Biowave DNA spectrophotometer (Biochrom WPA, Cambridge, UK) to measure the concentration and purity of the obtained RNA and then stored at $-80^{\circ} \mathrm{C}$ for subsequent analyses. Finally, the integrity of extracted RNA was evaluated by electrophoresis.

QRT-PCR

The extracted RNA samples were pretreated with Amplification Grade DNase Kit (Sigma-Aldrich, St. Louis, MO, USA), to eliminate any contamination by DNA. Reverse transcription was performed using the kit iScripTMcDNA Synthesis Kit (BIO-RAD, Milan, Italy).

qRT-PCR was performed using the iQ TM SYBR®Green Supermix kit (BIORAD, Milan, Italy). The primers used for the (GAPDH) glyceraldehyde 3-phosphate dehydrogenase (F: GATTTGGCCGTATCGGAC; R: GAAGACGCCAGTAGACTC) and $\beta$-actin (F: GGCTGTATTCCCCTCCATCG; R: CCAGTTGGTAACAATGCCATGT) were designed by using the Primer Express ${ }^{\circledR}$ Software v3.0.1 (Applied Biosystems®, Foster City, CA, USA), while for Sirt1, Sirt3 and NGF, primers reported in the literature were used (Cheung 2015; Zhang 2015). For the PCR reaction, the following mix was used: $50 \mathrm{ng}$ of cDNA, $300 \mathrm{nM}$ of each primer, 7.5 $\mu \mathrm{l}$ of Master Mix iQ SYBR Green Supermix and $5.6 \mu \mathrm{l}$ of $\mathrm{H} 2 \mathrm{O}$ DNase-free to a final volume of $15 \mu \mathrm{l}$. Samples were loaded in triplicate and the analysis was performed by the MiniOpticon Real-Time PCR Detection System 
I week
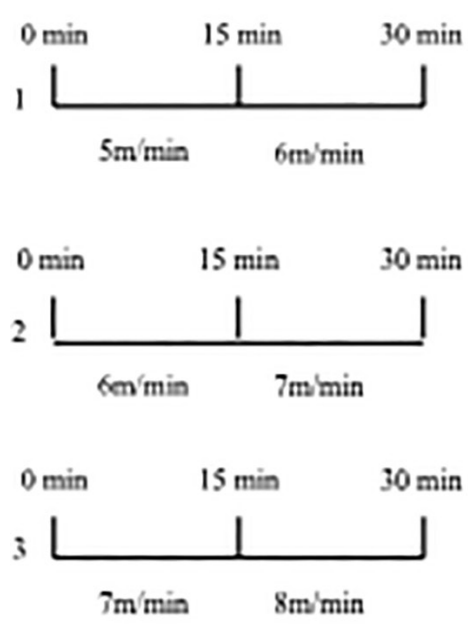

IV week
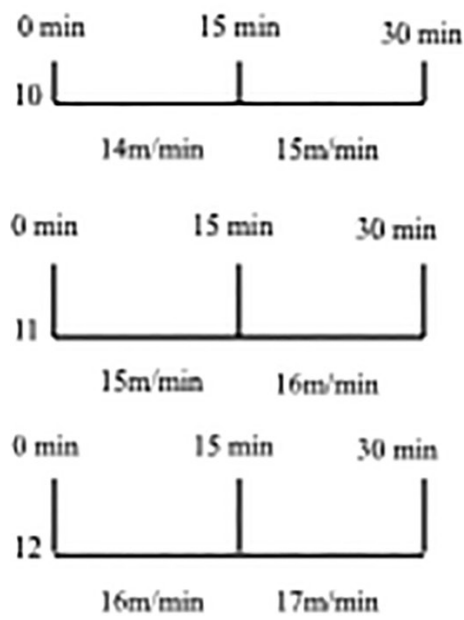

II week
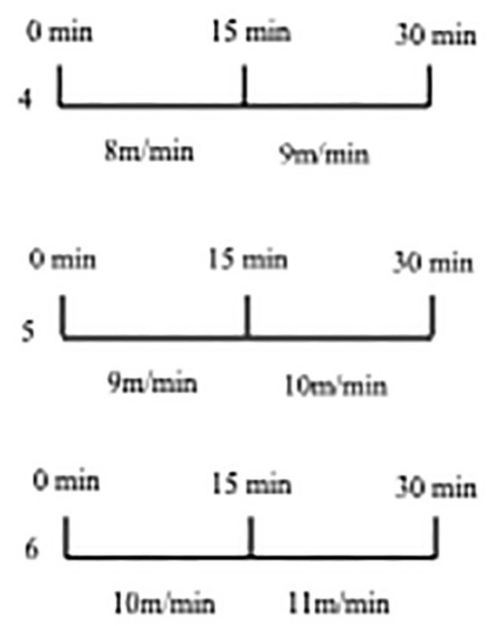

V week
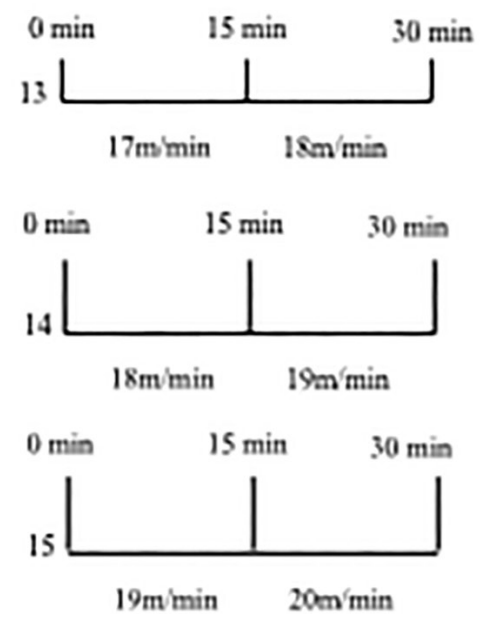

III week
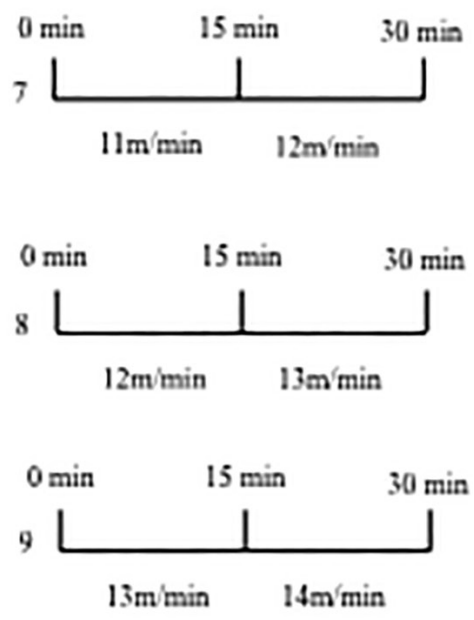

\section{VI week}
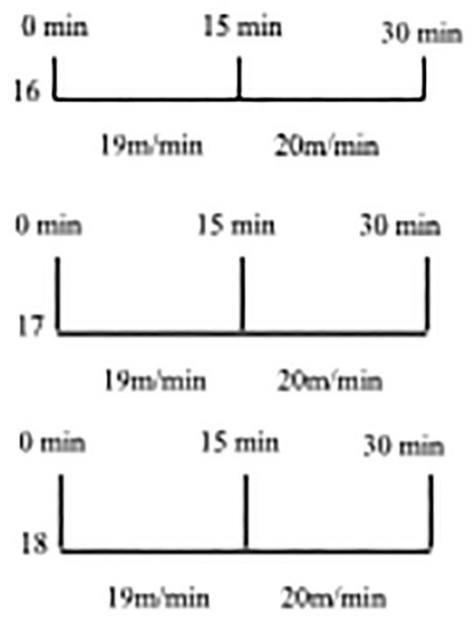

Fig. 1. - List of the eighteen exercise sessions of the six-week training protocol.

(BIO-RAD, Milan, Italy) and the Bio-Rad CFX Manager software. Cycling conditions included an initial denaturation $\left(3 \mathrm{~min}\right.$ at $95^{\circ} \mathrm{C}$ ) followed by 40 cycles of amplification and quantification (10 sec at $95^{\circ} \mathrm{C}, 60 \mathrm{sec}$ at $59^{\circ} \mathrm{C}$ with a single fluorescent measurement at the end of each elongation step) and dissociation protocol (from $60^{\circ} \mathrm{C}$ to $95^{\circ} \mathrm{C}$ by $1{ }^{\circ} \mathrm{C}$ increments followed by a $30 \mathrm{sec}$ hold and fluorescent measurement). Each target gene (SIRT1, SIRT3, and NGF) was amplified together with GAPDH and $\beta$-actin, as housekeeping genes. The relative evaluation of gene expression changes was performed by the $2^{-\Delta \Delta C T}$ method (Livak 2011). The data obtained for each sample in triplicate were represented in the graphs as means $\pm \mathrm{SE}$.

\section{Total Oxyradical Scavenging Capacity (TOSC) Assay}

The plasma antioxidant capability (AOC) was assessed by the TOSC assay, a gas chromatographic assay for determining oxyradical scavenging capacity of biological fluids (Regoli 1999). Peroxyl radicals 
were generated by the thermal homolysis of 20 $\mathrm{mM}$ 2,20-azo-bisamidinopropane (ABAP) at $35^{\circ} \mathrm{C}$ in $100 \mathrm{mM}$ potassium phosphate buffer, $\mathrm{pH}$ 7.4. Hydroxyl radicals were generated at $35^{\circ} \mathrm{C}$ by the iron plus ascorbate-driven Fenton reaction $(1.8 \mathrm{mM}$ $\mathrm{Fe} 3+, 3.6 \mathrm{mM}$ EDTA, and $180 \mathrm{mM}$ ascorbic acid in $100 \mathrm{mM}$ potassium phosphate buffer, $\mathrm{pH}$ 7.4). Peroxynitrite was generated from the decomposition of 3-morpholinosydnonimine N-ethylcarbamide (SIN1) in the presence of $0.2 \mathrm{mM}$ a-cheto-g-(methylthiol) butyric acid (KMBA), $100 \mathrm{mM}$ potassium phosphate buffer, $\mathrm{pH} 7.4$, and $0.1 \mathrm{mM}$ Diethylene Triamine Penta Acetic Acid (DTPA) at $35^{\circ} \mathrm{C}$. The concentration of SIN-1 was varied to achieve an ethylene yield equivalent to the iron-ascorbate and ABAP systems. Reactions with $0.2 \mathrm{mM} \mathrm{KMBA}$ were carried out in $10 \mathrm{ml}$ vials sealed with gas-tight Mininert1 valves (Supelco, Bellefonte, PA) in a final volume of $1 \mathrm{ml}$ (Regoli 1999). Ethylene production was measured by gas-chromatographic analysis of $200 \mathrm{ml}$ aliquots taken from the headspace of vials at timed intervals during the course of the reaction. Analyses were performed with a Hewlett-Packard gas chromatograph (HP 7820A Series, Andoven, MA) equipped with a Supelco DB-1 (30 x 0.32 x 0.25 $\mathrm{mm}$ ) capillary column and a flame ionization detector (FID). The oven, injection and FID temperatures were respectively 35,160 and $220^{\circ} \mathrm{C}$. Hydrogen was the carrier gas (flow rate of $1 \mathrm{ml} / \mathrm{min}$ ) and a split ratio of 20:1 was used. Total ethylene formation was quantified from the area under the kinetic curves that best define the experimental points obtained for control reactions and after addition of plasma during the reaction. TOSC values were quantified from the equation TOSC $=100$ - (SA/CA x 100), where SA and $\mathrm{CA}$ are the area under the curve (AUC) for sample and control reaction respectively. A TOSC value of 0 corresponds to a sample with no scavenging capacity. A TOSC value of 100 is attributed to a compound that entirely suppresses the ethylene formation whereas a pro-oxidant compound shows a negative TOSC value. Consequently, antioxidants and pro-oxidant molecules can be distinguished by the obtained results. The linearity of the dose-response curve between hippocampal homogenate $(\mu \mathrm{l})$ and the antioxidant response (TOSC value) was tested and good correlation coefficients (generally greater than 0.9 ) were obtained at the different doses used to test the validity of our experiments. Each experiment was performed in triplicate to account for the intrinsic variability of the method. The results obtained with plasma were expressed in TOSC units. In our study, the coefficient of variation (CV) of the method ranged between 2\% and 5\% (Bianchi 2016).

\section{Statistical Analysis}

All the data were expressed as means \pm SE since they were normally distributed according to the method of Kolmogorov-Smirnov. Comparisons within groups were performed with nonparametric ANOVA for repeated measurements and the Bonferroni post-hoc test. The statistical analyses of the data obtained with the 2- $\Delta \Delta \mathrm{CT}$ method and the TOSC assay were performed using the Student's t test for unpaired data. Statistical significance was set at $p<0.05$. The analyses were conducted using the software Prism 4.0 (GraphPad Software Inc., San Diego, CA, USA).

\section{Results}

At the end of the adaptation week (session 0 in Figure 1) experimental animals had walked an average of $134.49 \mathrm{~m}$, adapting to walk continuously for 30 minutes. In general, the animals chose to walk following the anticlockwise direction of the wheel. In session 1, the rats travelled an average of $215.75 \mathrm{~m}$, starting from an initial speed of $5 \mathrm{~m} / \mathrm{min}$, increased to $6 \mathrm{~m} / \mathrm{min}$ in the last 15 minutes, thus increasing significantly, compared to the period of adaptation, the distance travelled (ANOVA for repeated measures, $\mathrm{F}$ $(18,94)=1125, \mathrm{p}<0.0001$; Bonferroni post hoc test, $\mathrm{p}<0.01$ ). In session 2 , the starting speed was $6 \mathrm{~m} / \mathrm{min}$, increased to $7 \mathrm{~m} / \mathrm{min}$; thus, the speed was gradually increased up to $20 \mathrm{~m} / \mathrm{min}$ at the end of session 15 , in which the rats travelled an average of $452.65 \mathrm{~m}$. When the speed was increased above $20 \mathrm{~m} / \mathrm{min}$, the animal showed signs of fatigue; for this reason it was decided to maintain the increase achieved in session $15(19 \mathrm{~m} / \mathrm{min}$ to $20 \mathrm{~m} / \mathrm{min})$, even in the last three training sessions. At the end of the sixth week, the animals were able to walk an average of $537.20 \mathrm{~m}$ (Figure 2), achieving a significantly greater distance at each subsequent session except for sessions 6, 8, 11, 12, 14 and 15.

Since the literature suggests that exercise increases the transcriptional levels of neurotrophins, 


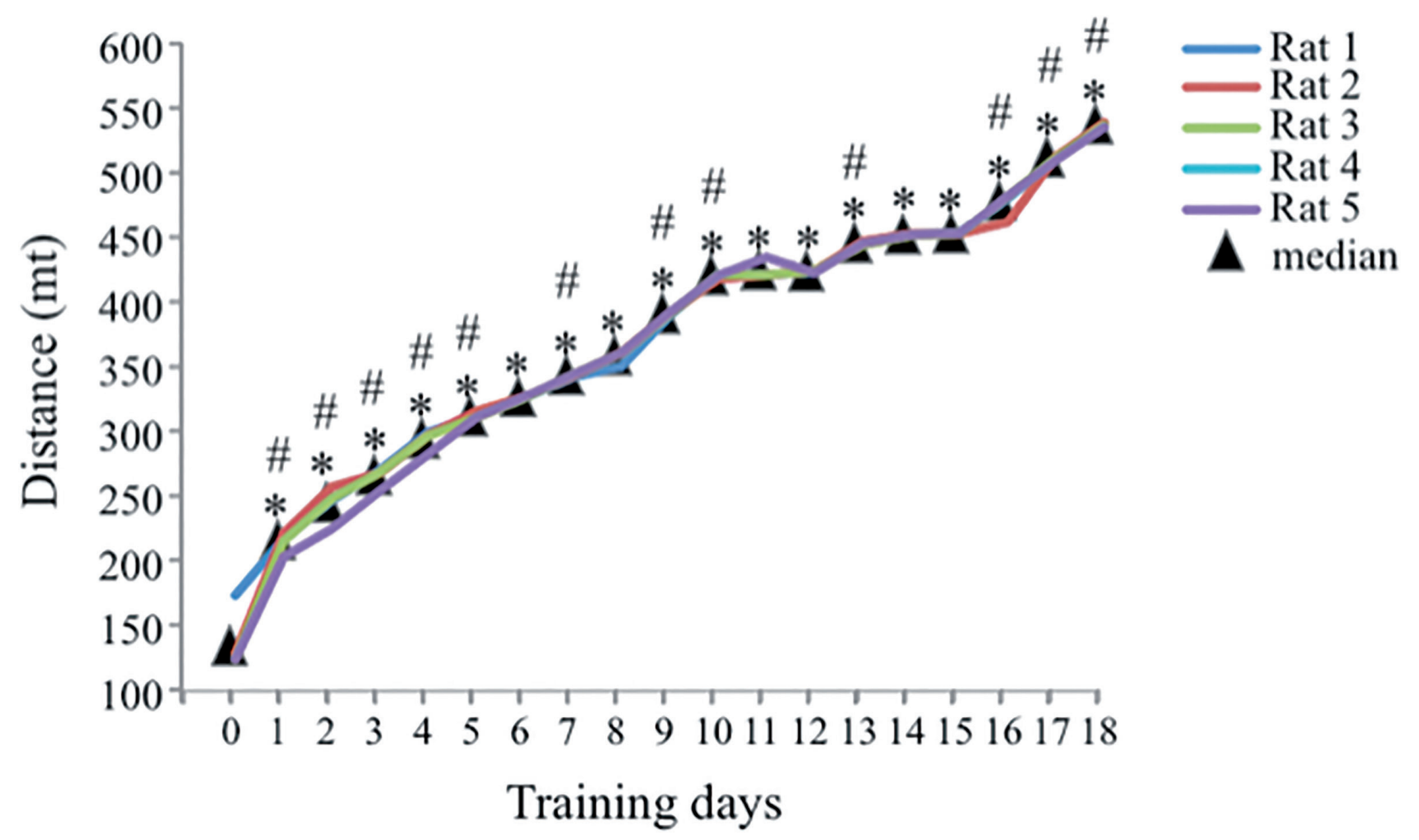

Fig. 2. - Distance reached by each animal after the eighteen test sessions.

particularly in the hippocampus (Mahjoub 2016), and that the exercise-induced antioxidant status may be regulated by the expression of Sirtuins (Koltai 2010), in the present study we investigated the levels of expression of the genes coding for NGF and for SIRT 1 and 3 in hippocampal tissue samples taken from trained and control rats. In trained rats compared to controls, the expression of NGF $(1.912 \pm 0.243$ vs $1.000 \pm 0.129$; t-test, df $=31$, $\mathrm{t}=2.235 ; \mathrm{p}=0.032)$ was significantly increased (Figure 3). The expressions of SIRT1 $(1.392 \pm 0.250$ vs $1.000 \pm 0.154 ; \mathrm{t}$ test, $\mathrm{df}=37, \mathrm{t}=0.812 ; \mathrm{p}=0.422$ ) and SIRT3 $(1.830 \pm 0.217$ vs $1.000 \pm 0.123$; t test, $\mathrm{df}$ $=43, \mathrm{t}=1.879, \mathrm{p}=0.067$ ) were also increased, but they did not reach any statistical significance.

Previous studies on sirtuins have shown how some target molecules, through the deacetylase activity of these proteins, are involved in the modulation of the main antioxidant enzymes (Koltai 2010). This close connection between sirtuins and the reduction of oxidative stress led us to analyse the levels of antioxidant capacity in hippocampus tissue samples by TOSC assay (TOSCA). TOSCA analysis was performed to assess the scavenger capacity against peroxyl (ROO $\cdot)$, hydroxyl $(\cdot \mathrm{OH})$ radicals and against peroxynitrite derivatives $(\cdot \mathrm{ONOO})$. The trained rats exhibited a higher hippocampus antioxidant activity against peroxyl $(1.567 \pm 0.085$ vs $1.138 \pm 0.037$; $\mathrm{p}=0.0011, \mathrm{t}=3.754, \mathrm{df}=22)$ and hydroxyl $(2.114 \pm 0.053$ vs $1.936 \pm 0.05 ; \mathrm{p}=0.0367, \mathrm{t}=2.225$, df $=22$ ) radicals than sedentary rats (Figure 4). In addition, trained rats had a higher anti-peroxynitrite activity $(1.99 \pm 0.048$ vs $1.65 \pm 0.046 ; \mathrm{p}<0.0001, \mathrm{t}=$ 4.742 , df $=22$ ) than sedentary rats (Figure 4).

\section{Discussion}

Our data show that moderate and constant physical activity is able to induce an increase of NGF expression and of antioxidant activity in the rat hippocampus.

From a physiological point of view, exercise may be considered as a stressor. Physical activity, in fact, induces oxidative stress as it disrupts the production of ROS at the expense of antioxidant capacity, which is proportional to the exercise intensity (Droge 2002). Depending on their concentration, location, and context, ROS may be either "friends" 


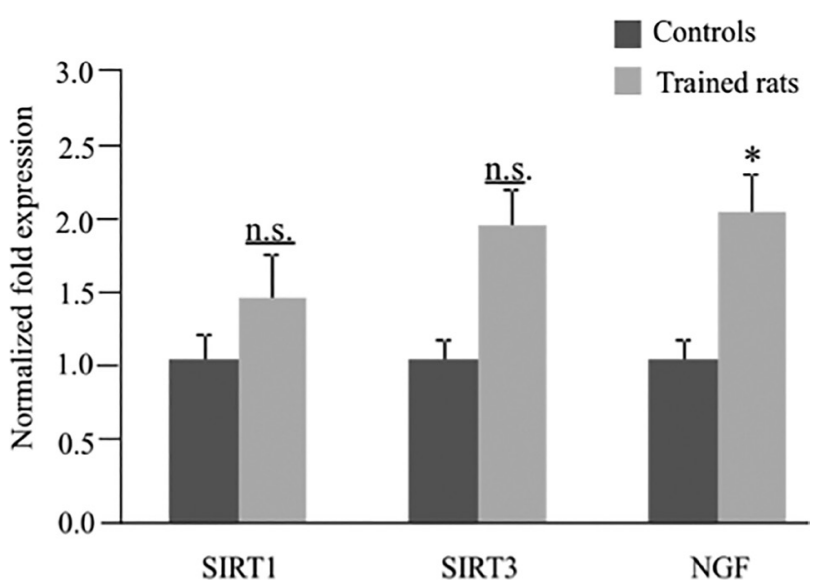

Fig. 3. - Gene expression levels following the workout training in trained and control rats. ${ }^{*} p=0.032$.

or "foes" according to the oxidant sensitivity of the iron- and myelin-rich central nervous system (CNS) (Camilletti-Moiron 2013). Conversely, physical exercise may also improve the reductionoxidation (redox) balance in the CNS by increasing the defensive mechanisms of antioxidants (Ristow 2010; Falone 2012), cell signalling and survival (Mattson 2000), and trophic factor expression (Mattson 2000; Radak 2006). In our study, we directly evaluated by TOSC assay the antioxidant activity of hippocampal tissue samples from trained rats compared to control rats. This assay is able to measure the anti-radical scavenging capacity towards various ROS (peroxyl and hydroxyl radicals and peroxynitrate derivate). Our data showed a significant increase in the scavenger activity towards peroxyl and hydroxyl radicals and the derivatives of peroxynitrite, after training. The increase in the antioxidant activity towards the hydroxyl radicals is of particular importance: this kind of free radicals represents the most toxic and reactive form of ROS, against which cell antioxidant pathway counter only partially by the limited production of glutathione peroxidase (Lubrano 2015). In addition, clinical practice shows that the antioxidants available on the market have poor efficacy against these radical species (Niedzwiecki 2016); therefore, the fact that moderate and regular exercise develops a good antioxidant activity against hydroxyl radicals is of particular interest. Furthermore, the exercise-induced anti-peroxynitrite activity is very important in light of the damage that derivatives of peroxynitrite are

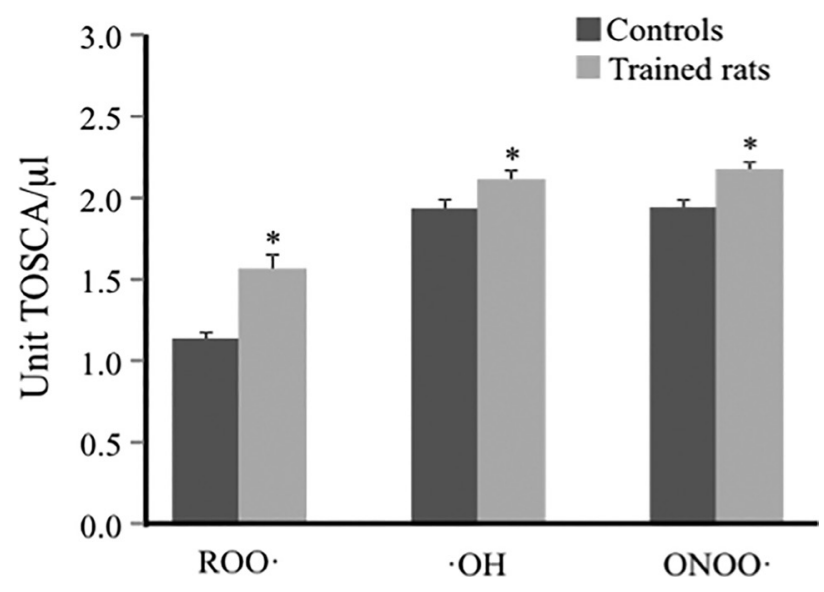

Fig. 4. - Hippocampal tissue antioxidant activity towards hydroxyl radicals (ROO.), peroxyl radicals $(\cdot \mathrm{OH})$, and the peroxynitrite derivatives (.ONOO) in trained and control rats. ${ }^{*} \mathrm{p}<0.05$.

able to induce. Peroxynitrite anion is formed from the diffusion-controlled reaction between the free radicals $\mathrm{NO}$ and $\mathrm{O}_{2} \cdot{ }^{-}(\mathrm{k} \sim 1010 \mathrm{M}-1 \mathrm{~s}-1)$ (Radi 2002) and has been related to various pathologies of the cardiovascular and central nervous systems (Szabó 2007; Levrand 2006).

Regarding the molecular mechanisms that enable physical activity to reduce oxidative stress, our study examined the role of sirtuins and NGF.

Sirtuins are sensitive to changes in the levels of the available $\mathrm{NAD}^{+}$and its intermediates (Dang 2014). Physical exercise increases the activity of sirtuins and consequently activates the activity of cell scavenging systems (SOD2, catalase, glutathione peroxidase, MnSOD) (Szabó 2007). Conversely, cellular aging reduces the activity of sirtuins (Chang 2014). Furthermore, the deacetylase activity of SIRT1 and SIRT3 is linked to the activity of the transcriptional coactivator of nuclear receptors PGC1 $\alpha$, which is a target molecule for SIRT1 and controls the transcription of SIRT3 (Kincaid 2013). In this cascade mechanism that affects SIRT1, SIRT3 and PGC1 $\alpha$, exercise would fit as an element that boosts the efficiency of the involved factors. However, it is not clear whether the activation of sirtuins depends on the increase in their gene expression, or on the increase in their deacetylase activity. Several literature studies describe the cellular localization, the ubiquity, the processes in which both these sirtuins are involved, the levels of their deacetylase activity (Pallas, 2008; Dang, 2014), but not the modulation of their gene expression. Here, we compared the gene expression of SIRT1 and SIRT3 in the hippocampus of rats exercised 
with regular moderate physical activity vs sedentary rats used as controls. In trained rats we observed a moderate increase in the expression of these two sirtuin genes that, however, did not reach any statistical significance. These findings, although preliminary, are very interesting and worthy to be replicated in a larger number of subjects.

We also investigated the expression of NGF, which is known to have stimulatory effects on differentiation, maintenance, and growth of neurons in peripheral and central nervous system (Cui 2007; Neeper 1996). We observed a significant increase of NGF gene expression in the hippocampus of trained rats compared to sedentary rats. With the exception of swimming exercise, performed 6 days per week for 4 weeks, that had no effect on NGF gene expression (Jiang 2014), previous studies found increases in NGF levels in several areas of the brain in response to aerobic exercise (Radak 2006). Our data confirm that aerobic physical activity increases NGF expression in rat hippocampus, probably by increasing the tissue antioxidant activity.

The hypothesis that exercise generally represents a protective factor for the entire body is no longer a hypothesis. Growing pieces of evidence in the scientific literature have been demonstrating that a moderate constant physical activity improves the quality of life, by inducing biochemical and physiological benefits throughout the body (Kramer 1999; Ferrari 2007; Train the brain study 2017; Franzoni 2005). In this work we observed that, in an adult animal model, a moderate and constant intensity workout over time contributes benefits also to the hippocampus, where it increases the expression of the gene coding for NGF and the specific antioxidant activity against all the radical species. Based on these results, we suggest that in adults, a regular physical exercise may counteract the effects of sedentary aging on hippocampal tissue, by increasing the antioxidant activity.

\section{References}

Bergersen L.H., Storm-Mathisen J. Training and brain health. Tidsskr Nor Laegeforen 126: 3253, 2006.

Bianchi S., Fusi J., Franzoni F., Giovannini L., Galetta F., Mannari C., Guidotti E., Tocchini L., Santoro G. Effects of recombinant human erythropoietin high mimicking abuse doses on oxidative stress processes in rats. Biomed Pharmacother, 82: 355-363, 2016.
Camiletti-Moiron D., Aparicio V.A., Aranda P., Radak Z. Does exercise reduce brain oxidative stress? a systematic review. Scand J Med Sci Sports, 23: e202-e212, 2013.

Chang H., Guarente L. SIRT1 and other sirtuins in metabolism. Trends Endocrinol Metab, 25 (3) 138$145,2014$.

Cheung K.G., Cole L.K., Xiang B., Chen K. Sirtuin-3 (SIRT3) Protein Attenuates Doxorubicin-induced Oxidative Stress and Improves Mitochondrial Respiration in H9c2 Cardiomyocytes. J Biol Chem, 290 (17): 10981-10993, 2015.

Clark P.J., Brzezinska W.J., Thomas M.W., Ryzhenko N.A., Toshkov S.A., Rhodes J.S. Intact neurogenesis is required for benefits of exercise on spatial memory but not motor performance or contextual fear conditioning in $\mathrm{C} 57 \mathrm{BL} / 6 \mathrm{~J}$ mice. Neuroscience 155 (4): 1048-1058, 2008.

Cui J., Shao L., Young L.T., Wang J.F. Role of glutathione in neuroprotective effects of mood stabilizing drugs lithium and valproate. Neurosc, 144: 1447-53, 2007.

Dang W. The controversial world of sirtuins. Drug Discov Today Technol, 12: e9-e17. 2014.

Droge W. Free radicals in the physiological control of cell function. Physiol Rev, 82: 47-95, 2002.

Droge W. Oxidative stress and aging. Adv Exp Med Biol 543: 191-200, 2003.

Falone S., D'Alessandro A., Mirabilio A., Cacchio M., Di Ilio C., Di Loreto S., Amicarelli F. Lateonset running biphasically improves redox balance, energy- and methylglyoxal-related status, as well as SIRT1 expression in mouse hippocampus. PLoS One, 7 (10): e48334, 2012.

Ferrari C.K. Functional foods and physical activities in health promotion of aging people. Maturitas $\mathbf{5 8}$ : 327-339, 2007.

Floyd R.A., Hensley K. Oxidative stress in brain aging. Implications for therapeutics of neurodegenerative diseases. Neurobiol Aging, 23: 795-807, 2002.

Franzoni F., Ghiadoni L., Galetta F., Plantinga Y., Lubrano V., Huang Y., Salvetti G., Regoli F., Taddei S., Santoro G., Salvetti A. Physical Activity, Plasma Antioxidant Capacity, and EndotheliumDependent Vasodilation in Young and Older Men. Am J Hypertens, 18 (4 Pt 1): 510-516, 2005.

Howitz K.T., Bitterman K.J., Cohen H.Y., Lamming D.W., Lavu S., Wood J.G., Zipkin R.E., Chung P., Kisielewski A., Zhang L.L., Scherer B., Sinclair D.A. Small molecule activators of sirtuins extend 
Saccharomyces cerevisiae life span. Nature, $\mathbf{4 2 5}$ (6954): 191-196, 2003.

Jiang P., Dang R., Li H., Zhang L., Zhu W.Y., Xue Y., Tang M.M. The impacts of swimming exercise on hippocampal expression of neurotrophic factors in rats exposed to chronic unpredictable mild stress. Evid. Based Compl. Alternat. Med, 729827, 2014.

Kayser B. Exercise starts and ends in the brain. Eur J Appl Physiol, 90: 411-419, 2003.

Kincaid B., Bossy Wetzel E. Forever young: SIRT3 a shield against mitochondrial meltdown, aging, and neurodegeneration. Front Aging Neurosci, 5: 48, 2013.

Koltai E., Szabo Z., Atalay M., Boldogh I., Naito H., Goto S., Nyakas C., Radak Z. Exercise alters SIRT1, SIRT6, NAD and NAMPT levels in skeletal muscle of aged rats. Mech Ageing Dev, 131 (1): 21-28, 2010.

Kramer A.F., Hahn S., Cohen N.J., Banich M.T., McAuley E., Harrison C.R., Chason J., Vakil E., Bardell L., Boileau R.A., Colcombe A. Ageing, fitness and neurocognitive function. Nature $\mathbf{4 0 0}$ (6443): 418-419, 1999.

Krause Neto W., Ciena A.P., Anaruma C.A., de Souza R.R., Gama E.F. Effects of exercise on neuromuscular junction components across age: systematic review of animal experimental studies. BMC Res Notes, 8: 713-727, 2015.

Levrand S., Vannay-Bouchiche C., Pesse B., Pacher P., Feihl F., Waeber B., Liaudet L. Peroxynitrite is a major trigger of cardiomyocyte apoptosis in vitro and in vivo. Free Radic Biol Med, 41 (6): 886-895, 2006.

Livak K.J., Schmittgen T.D. Analysis of relative gene expression data using real-time quantitative PCR and the 2(-Delta Delta C(T)) Method. Methods, 25 (4): 402-408, 2001.

Lubrano V., Balzan S. Enzymatic antioxidant system in vascular inflammation and coronary artery disease. World J Exp Med, 5: 218-224, 2015.

Mahjoub S., Ghadi A., Pourbagher R., HajianTilaki K., Masrour-Roudsari J. Effects of Regular Treadmill Exercise on a DNA Oxidative-Damage Marker and Total Antioxidant Capacity in Rat Hippocampal Tissue. J Clin Neurol, 12 (4): 414418, 2016.

Mariotti V., Melissari E., Amar S., Conte A., Belmaker R.H., Agam G., Pellegrini S. Effect of prolonged phenytoin administration on rat brain gene expression assessed by DNA microarrays. Exp Biol Med, 235 (3): 300-10, 2010.
Mattson M.P. Neuroprotective signaling and the aging brain: take away my food and let me run. Brain Res. 886 (1-2): 47-53, 2000.

Morris R.G. Elements of a neurobiological theory of hippocampal function: the role of synaptic plasticity, synaptic tagging and schemas. Eur $J$ Neurosci 23: 2829-2846, 2006.

Neeper S.A., Gómez-Pinilla F., Choi J., Cotman C.W. Physical activity increases mRNA for brainderived neurotrophic factor and nerve growth factor in rat brain. Brain Res, 726 (1-2): 49-56, 1996.

Niedzwiecki A., Roomi M.W., Kalinovsky T., Rath M. Anticancer Efficacy of Polyphenols and Their Combinations. Nutrients, 9; 8 (9): 2016.

Nisticò G., Ciriolo M.R., Fiskin K., Iannone M., De Martino A., Rotilio G. NGF restores decrease in catalase activity and increases superoxide dismutase and glutathione peroxidase activity in the brain of aged rats. Free Radic. Biol. Med, 12 (3): 1771-1781, 1992.

Nonato L.F., Rocha-Vieira E., Tossige-Gomes R., Soares A.A., Soares B.A., Freitas D.A., Oliveira M.X., Mendonc V.A., Lacerda A.C., Massensini A.R., Leite H.R. Swimming training attenuates oxidative damage and increases enzymatic but not non-enzymatic antioxidant defenses in the rat brain. Brazilian Journal of Medical and Biological Research, 49 (10): e5310, 2016.

Okamoto M., Hojo Y., Inoue K., Matsui T., Kawato S., McEwen B.S., Soya H. Mild exercise increases dihydrotestosterone in hippocampus providing evidence for androgenic mediation of neurogenesis. Proc. Natl. Acad. Sci. U.S.A. 109 (32): 1310013105, 2012.

Ozden O., Park S.H., Kim H.S., Jiang H., Coleman M., Spitz D.R., Gius D. Acetylation of MnSOD directes enzymatic activity responding to cellular nutrient status or oxidative stress. Aging, 3 (2): 102-107, 2011.

Pallas M., Verdaguer E., Tajes M., Gutierrez-Cuesta J., Camins A. Modulation of sirtuins: new targets for anti-ageing. Recent Patents CNS Drug Discov, 3 (1): 61-69, 2008.

Radak Z., Kaneko T., Tahara S., Nakamoto H., Ohno H., Sasvari M., Nyakas C., Goto S. The effect of exercise training on oxidative damage of lipids, proteins, and DNA in rat skeletal muscle: evidence for beneficial outcomes. Free Radic Biol Med 27: 69-74, 1999a.

Radak Z., Toldy A., Szabo Z., Siamilis S., Nyakas C., Silye G., Jakus J., Goto S. The effects of training 
and detraining on memory, neurotrophins and oxidative stress markers in rat brain. Neurochem Int, 49: 387-392, 2006.

Radi R., Cassina A., Hodara R., Quijano C., Castro L. Peroxynitrite reactions and formation in mitochondria. Free Radic. Biol. Med, 33 (11): 1451-1464, 2002.

Regoli F., Winston G.W. Quantification of total oxidant scavenging capacity of antioxidants for peroxynitrite, peroxyl radicals, and hydroxyl radicals. Toxicol. Appl. Pharmacol, 156 (2): 96-105, 1999.

Ristow M., Zarse K. How increased oxidative stress promotes longevity and metabolic health: The concept of mitochondrial hormesis (mitohormesis). Exp Gerontol; 45 (6): 410-418, 2010.

Serrano F., Klann E. Reactive oxygen species and synaptic plasticity in the aging hippocampus. Ageing Res Rev 3: 431-443, 2004.

Shin M.K. Effects of an exercise program on frontal lobe cognitive function in elders. J Korean Acad Nurs 39: 107-115, 2009.

Someya S., Yu W., Hallows W.C., Xu J., Vann J.M., Leeuwenburgh C., Tanokura M., Denu J.M., Prolla T.A. Sirt3 mediates reduction of oxidative damage and prevention of age-related hearing loss under caloric restriction. Cell, 143: 802-812, 2010.

Song W., Song Y., Kincaid B., Bossy B., BossyWetzel E. Mutant SOD1G93A triggers mitochondrial fragmentation in spinal cord motor neurons: neuroprotection by SIRT3 and PGC- $1 \alpha$. Neurobiol Dis, 51: 72-81, 2013.
Spina M.B., Squinto S.P., Miller J., Lindsay R.M., HymanC.Brain-derived neurotrophicfactorprotects dopamine neurons against 6-hydroxydopamine and N-methyl-4-phenylpyridinium ion toxicity: involvement of the glutathione system. $J$. Neurochem., 59 (1): 99-106, 1992.

Szabó C., Ischiropoulos H., Radi R. Peroxynitrite: biochemistry, pathophysiology and development of therapeutics. Nat. Rev. Drug Discov; 6 (8): $662-$ 680, 2007.

Train the Brain Consortium. Randomized trial on the effects of a combined physical/cognitive training in aged MCI subjects: the Train the Brain study. Sci Rep. 7: 39471, 2017.

Trejo J.L., Carro E., Torres-Aleman I. Circulating insulin-like growth factor I mediates exercise-induced increases in the number of new neurons in the adult hippocampus. J. Neurosci. 21 (5): 1628-1634, 2001.

Van der Borght K., Kobor-Nyakas D.E., Klauke K., Eggen B.J., Nyakas C., Van der Zee E.A., Meerlo $\mathrm{P}$. Physical exercise leads to rapid adaptations in hippocampal vasculature: temporal dynamics and relationship to cell proliferation and neurogenesis. Hippocampus 19 (10): 928-936, 2009.

Van Praag H., Kempermann G., Gage F.H. Running increases cell proliferation and neurogenesis in the adult mouse dentate gyrus. Nat. Neurosci. 2 (3): 266-270, 1999.

Zhang L., Fang Y., Lian Y., Chen Y. Brain-derived neurotrophic factor ameliorates learning deficits in a rat model of Alzheimer's disease induced by aß1-42. PLoS One, 10 (4): e0122415, 2015. 